\title{
$\underline{\mathbf{P}-118}$
}

\section{Role of Habbatus Sauda Towards the Histological Features of Nicotine Treated Male Rats Seminal Vesicle and Prostate Gland}

\author{
S. Lina ${ }^{1, *}$, N.H. Hashida ${ }^{2}$ and H. Eliza ${ }^{3}$ \\ ${ }^{1}$ Institute of Graduate Studies, ${ }^{2}$ Division of Biology, Center For Foundation Studies in Science, ${ }^{3}$ Department of \\ Anatomy, Faculty of Medicine, University of Malaya, 50603, Kuala Lumpur; E-mail: lina_samsudin89@yahoo.com
}

Habbatus sauda (Nigella sativa) is a plant commonly used as herbal medicine for treatment of diseases while nicotine is an addictive chemical that is present in cigarettes. The study was conducted to observe effects of habbatus sauda oil on histological features of nicotine treated male rats' seminal vesicles and prostate glands. Rats were divided into five groups: corn oil (COhabbatus sauda control), habbatus sauda (HS), saline (S-nicotine control), nicotine (N) and nicotine-habbatus sauda (N-HS). The CO and HS groups were force-fed with $0.1 \mathrm{ml} / 100 \mathrm{~g}$ and $6 \mu \mathrm{l} / 100 \mathrm{~g}$, respectively. The $\mathrm{S}$ and $\mathrm{N}$ groups were intramuscularly (i.m.) injected with $0.1 \mathrm{ml} / 100 \mathrm{~g}$ and $5.0 \mathrm{mg} / 100 \mathrm{~g}$, respectively. The N-HS group was treated with the same dosage as the $\mathrm{N}$ and HS groups. The treatment was conducted for 100 days. The prostate glands and seminal vesicles of animals in the $\mathrm{N}$ group showed reduction in the epithelial height of the mucosal linings compared to that of in the S, CO, HS and N-HS groups. Moreover, there was also less acidophilic secretion found in the glands of the animals in $\mathrm{N}$ group compared to the other 4 groups. However, the histology of the prostate glands and seminal vesicles in the N-HS group was noted to be similar to that of in the control ( $\mathrm{S}$ and $\mathrm{CO}$ ) groups. Hence, this suggested that administration of habbatus sauda oil could lead to an improvement in histology and function of both prostate glands and seminal vesicles in the nicotine treated rats. 